\title{
A Game-Theoretic Analysis of Fiscal Policy under Economic Growth from the Perspective of MMT: Toward a Neoclassical Basis of MMT
}

\author{
YASUHITO TANAKA \\ Faculty of Economics \\ Doshisha University \\ Kamigyo-ku, Kyoto, 602-8580
}

JAPAN

\begin{abstract}
We present a game-theoretic analysis of fiscal policy under economic growth from the perspective of MMT using a simple two-periods overlapping generations (OLG) model. We show the following results. 1) Sustained budget deficits are necessary to maintain full-employment under economic growth driven by population growth. 2) An excessive budget deficit triggers inflation, and after one period inflation full-employment is maintained by sustained budget deficits with constant price. 3) Insufficient government deficit causes involuntary unemployment, and we need extra budget deficit over its steady state value to recover full-employment. These budget deficits need not be, and must not be redeemed. Therefore, if it is institutionally and legally possible, they should be financed by seigniorage not by public debt.
\end{abstract}

Key-Words: - Overlapping generations model, Full-employment, Budget deficit, Growth, MMT

Received: June 15, 2021. Revised: January 26, 2022. Accepted: February 17, 2022. Published: March 3, 2022.

\section{Introduction}

This paper will present a game theoretic analysis of a simple two-periods overlapping generations (OLG) model with pay-as-you-go pensions in which goods are produced solely by labor, and mainly show the following three results.

1. Sustained budget deficits are necessary to maintain full-employment under economic growth driven by population growth. Budget deficit is necessary under growth because of deficiency of the consumptions by the older generation consumers. Since the budget deficits to maintain full-employment must be sustained, if it is institutionally and legally possible, the budget deficits should be financed by seigniorage not by public debt. This budget deficit need not to be, and must not be redeemed.

2. An excessive budget deficit triggers inflation. About this excessive budget deficit that has caused inflation, only the excess portion should be reduced. There is no need to make up for past excesses by creating surpluses or reducing deficits.

3. Insufficient government deficit causes involuntary unemployment, and we need extra budget deficit over its steady state value to recover fullemployment. After recovery of full-employment we can maintain it with sustained budget deficits. Thus, the extra budget deficit should not be redeemed.

In the next section we present a model of this paper. In Section 3 we consider budget deficit for economic growth. In Section 4 we analyze inflation by excessive budget deficit, and in Section 5 we consider involuntary unemployment due to insufficient government deficit, and necessity of extra budget deficit to recover full-employment. In Section 6 we will consider a case of economic growth by technological progress instead of population growth.

This paper is one of the attempts to give a theoretical basis to the so-called functional finance theory by [3] and [4]. It also present a theoretical foundation to MMT (Modern Monetary Theory, [5]). In particular, we provide a rationale for the following claims ([2]). We refer to the summary of Kelton's book by [1]. In fact, Hogan argues that Kelton is wrong, but he summarizes Kelton's argument to the point.

1. The treasury creates new money.

The money supply equals the net savings (the savings minus the pay-as-you-go pensions). An increase in the money supply equals the increase in the net savings. As expressed in the equation (4) in Section 3.1, an increase in the net savings from a period to the next period equals the budget deficit in the latter period. The rate of an increase in the net savings, which equals the rate of in increase in the money supply, equals the rate of economic growth, and therefore the budget deficit and an increase in the money supply does not cause inflation in this case.

2. Inflation is caused by federal government deficit spending, not by Fed policy.

As we will show in Section 4.1, if the actual budget deficit is larger than the budget deficit that is necessary and sufficient to maintain fullemployment under economic growth with constant price, the price of the good will rise. 
3. Federal government spending is not related to taxes or borrowing.

As summarized above, sustained budget deficits are necessary to maintain full-employment under economic growth, and these budget deficits make it possible to maintain full-employment. It is impossible to maintain full-employment in a growing economy with a balanced budget. Therefore, even if the budget deficit to maintain fullemployment is financed by the national debt, it does not need to be repaid or redeemed, and must not be repaid or redeemed. Future budget surpluses need not and must not make up the deficits for growth.

Recently, we have published some studies about theoretical or mathematical bases of MMT using a model with or without microeconomic foundations of behaviors of consumers and firms under perfect or monopolistic completion (for example, [10], [11], [12]). This paper is an attempt to interprete these results in the framework of Game Theory.

\section{The model}

We consider the following model. It is a two generations overlapping generations (OLG) model, and a simplified version of the model used by [6], [7], [8] and [9] with pay-as-you-go pensions.

1. There are one good and one firm. The firm produces one unit of the good by one unit of labor at present (Period $t$ ). Although there is only one firm, it behaves competitively. Let $w$ be the nominal wage rate and $p$ be the price of the good. Then, $p=w$, and the real wage rate is one.

2. Consumers live over two periods, Period 1 and Period 2. In Period 1 (younger period, working period) they can work and earn the wages. They buy and consume the good by wages. In Period 2 (older period, retired period) they buy and consume the good by their savings and the pay-asyou-go pensions. The good can be consumed by any unit, that is, a consumer can consume, for example, 0.1 units of the good. The population of consumers grows from a period to the next period at the rate $\gamma-1>0$.

3. There are four younger generation consumers in Period $t$. If a consumer is employed, he supplies one unit of labor (labor supply is indivisible), receives the wage, consumes the good, pays tax for pay-as-you-go pensions for consumers of the older generation, lends money to unemployed younger generation consumers (if involuntary unemployment exists) and leaves the remaining income.
If a consumer is not employed, his income is zero. However, he can receive a pay-as-yougo pension after retirement, so he consumes the good in his Period 1 by borrowing money from employed younger generation consumers using his pension as collateral. We assume that utility of an employed consumer is larger than utility of an unemployed consumer.

Each consumer determines his consumption and labor supply at the beginning of Period 1 depending on the situation that he is employed or not employed. He spends half of his income, respectively, on consumption in Period 1 and that in Pe$\operatorname{riod} 2$.

4. There are $\frac{4}{\gamma}$ older consumers in Period $t$ (four older generation consumers in Period $t+1$ ). If a consumer was employed in his Period 1, he consumes the good by his savings and the pay-asyou-go pension. If he is not employed, he consumes the good only by the pay-as-you-go pension, and repays his debt due to consumption in Period 1.

We assume zero interest rate. Repayment by a consumer who was unemployed in the younger period is assured. An employed consumer is indifferent between lending money to unemployed consumers and leaving money.

We assume that the tax other than that for the payas-you-go pension system is zero.

\section{Sustained full-employment under growth with constant price}

\subsection{Period $t$}

Let us consider the following pair of strategies of the firm and the younger generation consumers at a steady state with full-employment and constant price under economic growth due to population growth at the rate $\gamma-1$. The strategies of the consumers are derived from their utility maximization over two periods. Denote the pay-as-you go pension received by each older generation consumer in each period is $\gamma \tau$. On the other hand, the tax for the pay-as-you-go pension paid by each younger generation consumer is $\tau$ because of the population growth. The nominal wage rate and the price are 1 .

1. Firm: employs four younger generation consumers and produces four units of the good.

2. Each employed younger generation consumer: supplies one unit of labor, receives wage 1 , consumes $\frac{1}{2}[1+(\gamma-1) \tau]$ units of the good, pays $\tau$ units of tax for the pay-as-you-go pension system 
for the older generation consumers, and leaves the rest of the income;

$$
\frac{1}{2}[1-(1+\gamma) \tau] .
$$

In the next period he consumes $\frac{1}{2}[1+(\gamma-1) \tau]$ units of the good by his savings and the pay-asyou-go pension $\gamma \tau$.

Each older generation consumer consumes $\frac{1}{2}[1+(\gamma-$ 1) $\tau$ ] units of the good by his savings and the pay-asyou-go pension $(\gamma \tau)$. Let $G^{t}$ be the government expenditure other than the pay-as-you-go pension. The total demand for the good is

$$
2\left(1+\frac{1}{\gamma}\right)[1+(\gamma-1) \tau]+G^{t}
$$

Note that there are four younger and $\frac{4}{\gamma}$ older generation consumers. This must be equal to the total supply, 4. Thus,

$$
G^{t}=\frac{2(\gamma-1)}{\gamma}[1-(1+\gamma) \tau]>0 .
$$

The total net savings of the older generation consumers, which is the difference between their consumptions and the pensions, is

$$
\frac{2}{\gamma}[1+(\gamma-1) \tau]-\frac{4}{\gamma} \gamma \tau=\frac{2}{\gamma}[1-(1+\gamma) \tau] .
$$

On the other hand, the total net savings of the older generation consumers in the next period, who are the younger generation consumers in Period $t$, is

$$
2[1+(\gamma-1) \tau]-4 \gamma \tau=2[1-(1+\gamma) \tau] .
$$

The difference between (3) and (2) is

$$
\frac{2}{\gamma}(\gamma-1)[1-(1+\gamma) \tau]=G^{t} .
$$

Therefore, the government expenditure $G^{t}$ in (1) equals the increase in the net savings of the consumers from Period $t-1$ to Period $t$. rium?

Is the pair of strategies above in a Nash equilib-

1. Firm: given the consumption behavior of the younger generation consumers and the older generation consumers, and the government expenditure, employment of four consumers and production of four units of the good are optimal.

2. Each younger generation consumer: given the behavior of the firm, consumptions of the other consumers and the government expenditure, supply of one unit of labor and $\frac{1}{2}[1+(\gamma-1) \tau]$ units of consumption are optimal under the assumption that each consumer spends half of his income, respectively, on consumption in Period 1 and that in Period 2.

Since we assume zero tax other than the tax for the pay-as-you-go pension system, the government expenditure equals the budget deficit, and the existence of the positive government expenditure means the existence of the budget deficit. Since the budget deficits to maintain full-employment must be sustained, if it is institutionally and legally possible, the budget deficits should be financed by seigniorage not by public debt. Budget deficit is necessary under growth because of deficiency of the savings of the older generation. This budget deficit is not debt and does not need to be, and must not be redeemed.

Since consumers leave the savings by money, the money supply equals the net savings (the savings minus the pay-as-you-go pensions). An increase in the money supply equals the increase in the net savings. As expressed in the equation (4), an increase in the net savings from Period $t-1$ to Period $t$ equals the budget deficit in Period $t$. The rate of an increase in the net savings, which equals the rate of in increase in the money supply, equals the rate of economic growth, and therefore the budget deficit and an increase in the money supply does not cause inflation in this case.

\subsection{Period $t+1$}

Next we consider Period $t+1$. Let us consider the following pair of strategies of the firm and the younger generation consumers in Period $t+1$.

1. Firm: employs $4 \gamma$ younger generation consumers and produces $4 \gamma$ units of the good.

2. Each employed younger generation consumer: supplies one unit of labor, receives wage 1 , consumes $\frac{1}{2}[1+(\gamma-1) \tau]$ units of the good, pays $\tau$ units of tax for the pay-as-you-go pension system for the older generation consumers, who are the younger generation consumers in Period $t$, and leaves the rest of the income;

$$
\frac{1}{2}[1-(1+\gamma) \tau] .
$$

In the next period he consumes $\frac{1}{2}[1+(\gamma-1) \tau]$ units of the good by his savings and the pay-asyou-go pension $\gamma \tau$.

Each older generation consumer consumes $\frac{1}{2}[1+(\gamma-$ 1) $\tau$ ] units of the good by his savings and the pay-asyou-go pension $(\gamma \tau)$. Let $G^{t+1}$ be the government expenditure other than the pay-as-you-go pension. The 
total demand for the good is

$$
2(1+\gamma)[1+(\gamma-1) \tau]+G^{t+1} .
$$

This must be equal to the total supply, $4 \gamma$. Thus,

$$
G^{t+1}=2(\gamma-1)[1-(1+\gamma) \tau]=\gamma G^{t} .
$$

The government expenditure $G^{t+1}$ in (5) equals the increase in the net savings of the consumers from Period $t$ to Period $t+1$. This relationship holds true even after Period $t+1$.

Is the pair of strategies above in a Nash equilibrium?

1. Firm: given the consumption behavior of the younger generation consumers and the older generation consumers, and the government expenditure, employment of four consumers and production of $4 \gamma$ units of the good are optimal.

2. Each younger generation consumer: given the behavior of the firm, consumptions of the other consumers and the government expenditure, supply of one unit of labor and $\frac{1}{2}[1+(\gamma-1) \tau]$ units of consumption are optimal under the assumption that each consumer spends half of his income, respectively, on consumption in Period 1 and that in Period 2.

From these results we get the following proposition.

Proposition 1. In order to maintain economic growth we need sustained budget deficits. The budget deficit in each period equals the increase in the total net savings of the older generation consumers (the difference between their consumptions and the pensions) from the previous period to this period.

\section{Inflation by excessive budget deficit}

\subsection{Period $t$}

In this section we suppose that the government expenditure in Period $t$ is larger than $G^{t}$ in the previous case. Denote it by $\hat{G}^{t}$. The actual price of the good in Period $t$ is $\rho>1$, and the actual nominal wage rate is also $\rho$. We assume that the inflation is not anticipated by the older generation consumers in the previous period (when they are young in their Period 1). We consider the value of $\hat{G}^{t}$ which triggers inflation at the rate $\rho$ under full-employment. Let us consider the following pair of strategies of the firm and the younger generation consumers.

1. Firm: employs four younger generation consumers and produces four units of the good.
2. Each employed younger generation consumer: supplies one unit of labor, receives wage $\rho$, consumes $\frac{1}{2}[1+(\gamma-1) \tau]$ units of the good at the price $\rho$, pays $\rho \tau$ units of tax for the pay-as-yougo pensions for the older generation consumers, and leaves the rest of the income;

$$
\rho-\rho \tau-\frac{\rho}{2}[1+(\gamma-1) \tau]=\frac{\rho}{2}[1-(1+\gamma) \tau] .
$$

In the next period he consumes $\frac{1}{2}[1+(\gamma-1) \tau]$ units of the good by his savings and the pay-asyou-go pension $\rho \gamma \tau$ at the price $\rho$ if the price of the good is $\rho$ in Period $t+1$.

Each older generation consumer consumes $\frac{1}{2 \rho}[1+$ $(\rho \gamma-1) \tau]$ units of the good by his savings and the pay-as-you-go pension $(\rho \gamma \tau)$. The nominal total demand for the good is

$$
\begin{aligned}
& 2 \rho[1+(\gamma-1) \tau]+\frac{2}{\gamma}[1+(\rho \gamma-1) \tau]+\hat{G}^{t} \\
= & \frac{2}{\gamma}\left[1+\rho \gamma+\left(\rho \gamma^{2}-1\right) \tau\right]+\hat{G}^{t} .
\end{aligned}
$$

If this is equal to the nominal total supply, $4 \rho$, we have

$$
\hat{G}^{t}=\frac{2}{\gamma}\left[\rho \gamma-1-\left(\rho \gamma^{2}-1\right) \tau\right] .
$$

Comparing this with $G^{t}$ in (1),

$$
\begin{aligned}
& \hat{G}^{t}-G^{t} \\
& \quad=\frac{2}{\gamma}\left\{\rho \gamma-1-\left(\rho \gamma^{2}-1\right) \tau-(\gamma-1)[1-(1+\gamma) \tau]\right\} \\
& \quad=2(\rho-1)(1-\gamma \tau)>0 .
\end{aligned}
$$

This means that an excessive budget deficit expressed in (6) causes inflation under full-employment.

Is the pair of strategies above in a Nash equilibrium?

1. Firm: given the consumption behavior of the younger generation consumers and the older generation consumers, and the government expenditure, employment of four consumers and production of four units of the good are optimal.

2. Each younger generation consumer: given the behavior of the firm and consumptions of the other consumers, supply of one unit of labor and $\frac{1}{2}[1+(\gamma-1) \tau]$ units of consumption are optimal under the assumption that each consumer spends half of his income, respectively, on consumption in Period 1 and that in Period 2.

From these results we get the following proposition.

Proposition 2. The excessive budget deficit expressed in (6) causes inflation under full-employment. 


\subsection{Period $t+1$}

Next we consider Period $t+1$. Let us consider the following pair of strategies of the firm and the younger generation consumers in Period $t+1$. The pay-asyou-go pension for each older generation consumer is $\rho \gamma \tau$. Assume that the price of the good in this period is $\rho$.

1. Firm: employs $4 \gamma$ younger generation consumers and produces $4 \gamma$ units of the good.

2. Each employed younger generation consumer: supplies one unit of labor, receives wage $\rho$, consumes $\frac{1}{2}[1+(\gamma-1) \tau]$ units of the good at the price $\rho$, pays $\rho \gamma \tau$ units of tax for pay-as-you-go pension to the older generation consumers, who are the younger generation consumers in Period $t$, and leaves the rest of the income;

$$
\rho-\rho \tau-\frac{\rho}{2}[1+(\gamma-1) \tau]=\frac{\rho}{2}[1-(1+\gamma) \tau] .
$$

In the next period he consumes $\frac{1}{2}[1+(\gamma-1) \tau]$ units of the good by his savings and the pay-asyou-go pension $\rho \gamma \tau$ at the price $\rho$.

Each older generation consumer consumes $\frac{1}{2}[1+(\gamma-$ 1) $\tau]$ units of the good by his savings and the pay-asyou-go pension $(\rho \gamma \tau)$ at the price $\rho$. Let $\hat{G}^{t+1}$ be the government expenditure other than the pay-as-you-go pension. The nominal total demand for the good is

$$
2 \rho(1+\gamma)[1+(\gamma-1) \tau]+\hat{G}^{t+1} .
$$

Note that there are $4 \gamma$ younger generation consumers. This must be equal to the nominal total supply, $4 \rho \gamma$. Thus,

$$
\hat{G}^{t+1}=2 \rho(\gamma-1)[1-(1+\gamma) \tau] .
$$

From (5) we find

$$
\hat{G}^{t+1}=\rho G^{t+1} .
$$

This relationship holds true even after Period $t+1$. Therefore, after one period inflation full-employment under constant price is maintained by sustained budget deficits. Only the excess portion should be reduced. There is no need to make up for past excesses by creating surpluses or reducing deficits. rium?

Is the pair of strategies above in a Nash equilib-

1. Firm: given the consumption behavior of the younger generation consumers and the older generation consumers, and the government expenditure, employment of four consumers and production of $4 \gamma$ units of the good are optimal.
2. Each younger generation consumer: given the behavior of the firm, consumptions of the other consumers and the government expenditure, supply of one unit of labor and $\frac{1}{2}[1+(\gamma-1) \tau]$ units of consumption are optimal under the assumption that each consumer spends half of his income, respectively, on consumption in Period 1 and that in Period 2.

From these results we obtain the following proposition.

Proposition 3. After one period inflation fullemployment under constant price is maintained by sustained budget deficits. Only the excess portion should be reduced. There is no need to make up for past excesses by creating surpluses or reducing deficits.

\section{Insufficient budget deficit and recovery from recession}

\subsection{Period $t$}

Now we assume that the government expenditure in Period $t$ is insufficient. Let the actual value of the government expenditure be

$$
\tilde{G}^{t}=\frac{2}{\gamma}(\gamma-1)[1-(1+\gamma) \tau]-\frac{1}{2} .
$$

It is smaller than $G^{t}$ in (1). We assume that it is nonnegative. The price of the good and the nominal wage rate in Period $t$ is 1 . We also assume that upto the previous period, Period $t-1$, full-employment has been realized. Let us consider the following pair of strategies of the firm and the younger generation consumers.

1. Firm: employs three younger generation consumers and produces three units of the good.

2. Each employed younger generation consumer: supplies one unit of labor, receives wage 1 , consumes $\frac{1}{2}\left[1+\left(\gamma-\frac{4}{3}\right) \tau\right]$ units of the good, pays $\frac{4}{3} \tau$ units of tax for pay-as-you-go pensions for the older generation consumers, and leaves the rest of the income:

$1-\frac{4}{3} \tau-\frac{1}{2}\left[1+\left(\gamma-\frac{4}{3}\right) \tau\right]=\frac{1}{2}\left[1-\left(\gamma+\frac{4}{3}\right) \tau\right]$.

In the next period he consumes $\frac{1}{2}\left[1+\left(\gamma-\frac{4}{3}\right) \tau\right]$ units of the good by his savings and the pay-asyou-go pension $\gamma \tau$.

3. One unemployed consumer: consumes $\frac{1}{2} \gamma \tau$ units of the good by borrowing money from employed younger generation consumers using his pension 
as collateral. In the next period he consumes $\frac{1}{2} \gamma \tau$ units of the good by the pay-as-you-go pension $\gamma \tau$, and repays his debt due to consumption in Period 1

Each older generation consumer consumes $\frac{1}{2}[1+$ $(\gamma-1) \tau]$ units of the good by his savings and the pay-as-you-go pension $(\gamma \tau)$. The total demand for the good is

$$
\begin{aligned}
& \frac{3}{2}\left[1+\left(\gamma-\frac{4}{3}\right) \tau\right]+\frac{1}{2} \gamma \tau \\
& +\frac{2}{\gamma}[1+(\gamma-1) \tau]+\tilde{G}^{t} \\
= & \frac{3}{2}\left[1+\left(\gamma-\frac{4}{3}\right) \tau\right]+\frac{1}{2} \gamma \tau+\frac{2}{\gamma}[1+(\gamma-1) \tau] \\
& +\frac{2}{\gamma}(\gamma-1)[1-(1+\gamma) \tau]-\frac{1}{2}=3 .
\end{aligned}
$$

Note that there are $\frac{4}{\gamma}$ older generation consumers, three employed and one unemployed younger consumers. (7) means that the total demand equals the total supply, and there exists one involuntary unemployment.

Are the strategies of the firm and the younger generation consumers above in a Nash equilibrium?

1. Firm: given the consumption behavior of the younger generation consumers and the older generation consumers, and the government expenditure, employment of three consumers and production of three units of the good are optimal.

2. Each younger employed consumer: given the behavior of the firm, consumptions of the other consumers and the government expenditure, supply of one unit of labor and $\frac{1}{2}\left[1+\left(\gamma-\frac{4}{3}\right) \tau\right]$ units of consumption are optimal under the assumption that each consumer spends half of his income, respectively, on consumption in Period 1 and that in Period 2.

3. One younger unemployed consumer: given the behavior of the firm, consumptions of the other consumers and the government expenditure, $\frac{1}{2} \gamma \tau$ units of consumption is optimal given the situation that he is unemployed, and spends half of his income, respectively, on consumption in Period 1 and that in Period 2. tion.

From these results we get the following proposi-

Proposition 4. The insufficient government expenditure (or budget deficit) causes involuntary unemployment.

\subsection{Period $t+1$}

Next we consider Period $t+1$. Suppose that we recover full-employment in Period $t+1$ by increasing the government expenditure (or the budget deficit). Let $\tilde{G}^{t+1}$ be the government expenditure other than the pay-as-you-go pension which is sufficient to recover full-employment.

Let us consider the following pair of strategies of the firm and the younger generation consumers in Period $t+1$. The pay-as-you-go pension for each older generation consumer is $\gamma \tau$. Assume that the price of the good in this period is 1 .

1. Firm: employs $4 \gamma$ younger generation consumers and produces $4 \gamma$ units of the good.

2. Each employed younger generation consumer: supplies one unit of labor, receives wage 1 , consumes $\frac{1}{2}[1+(\gamma-1) \tau]$ units of the good, pays $\tau$ units of tax for pay-as-you-go pension for the older generation consumers, who are the younger generation consumers in Period $t$, and leaves the rest of the income;

$$
1-\tau-\frac{\gamma}{2}[1+(\gamma-1) \tau]=\frac{1}{2}[1-(1+\gamma) \tau] .
$$

In the next period he consumes $\frac{1}{2}[1+(\gamma-1) \tau]$ units of the good by his savings and the pay-asyou-go pension $\gamma \tau$.

Each older generation consumer, who was employed in the previous period, consumes $\frac{1}{2}\left[1+\left(\gamma-\frac{4}{3}\right) \tau\right]$ units of the good by his savings and the pay-as-yougo pension $(\gamma \tau)$, and one older generation consumer, who was unemployed in the previous period, consumes $\frac{1}{2} \gamma \tau$ units of the good by the pay-as-you-go pension. He also repay the debt for consumption in the previous period.

The total demand for the good is

$2 \gamma[1+(\gamma-1) \tau]+\frac{3}{2}\left[1+\left(\gamma-\frac{4}{3}\right) \tau\right]+\frac{1}{2} \gamma \tau+\tilde{G}^{t+1}$.

Note that there are three older generation consumers who was employed, and one of them was unemployed. Suppose that this is equal to the total supply, $4 \gamma$. Then,

$$
\tilde{G}^{t+1}=2(\gamma-1)[1-(1+\gamma) \tau]+\frac{1}{2} .
$$

Comparing this with (5)

$$
\tilde{G}^{t+1}-G^{t+1}=\frac{1}{2}>0 .
$$

Therefore, to recover full-employment from a state with involuntary unemployment we need extra budget deficit. After recovery of full-employment we can 
maintain it with sustained budget deficit. Thus, the extra budget deficit should not be redeemed.

Is the pair of strategies above in a Nash equilibrium?

1. Firm: given the consumption behavior of the younger generation consumers and the older generation consumers, and the government expenditure, employment of four consumers and production of $4 \gamma$ units of the good are optimal.

2. Each younger generation consumer: given the behavior of the firm, consumptions of the other consumers and the government expenditure, supply of one unit of labor and $\frac{1}{2}[1+(\gamma-1) \tau]$ units of consumption are optimal under the assumption that each consumer spends half of his income, respectively, on consumption in Period 1 and that in Period 2. sition.

From these results we obtain the following propo-

Proposition 5. In order to recover full-employment from a state with involuntary unemployment we need extra budget deficit. After recovery of fullemployment we can maintain it with sustained budget deficit. Thus, the extra budget deficit should not be redeemed.

\section{Growth by technological progress}

\subsection{Sustained full-employment under growth with constant price}

\subsubsection{Period $t$}

Let us consider the following pair of strategies of the firm and the younger generation consumers at a steady state with full-employment and constant price under economic growth at the rate $\gamma-1$. The strategies of the consumers are derived from their utility maximization over two periods. We suppose that the labor productivity is 1 in Period $t$, and it increases at the rate $\gamma-1$. Also we assume that the nominal wage rate is 1 in Period $t$. Denote the pay-as-you go pension in this period by $\tau$. We assume

$$
(1+\gamma) \tau<1 \text {. }
$$

1. Firm: employs four younger generation consumers and produces four units of the good.

2. Each employed younger generation consumer: supplies one unit of labor, receives wage 1 , consumes $\frac{1}{2}[1+(\gamma-1) \tau]$ units of the good, pays $\tau$ units of tax for the pay-as-you-go pension system for the older generation consumers, and leaves the rest of the income;

$$
\frac{1}{2}[1-(1+\gamma) \tau]
$$

In the next period he consumes $\frac{1}{2}[1+(\gamma-1) \tau]$ units of the good by his savings and the pay-asyou-go pension $\gamma \tau$.

Since we consider a steady state under growth at the rate $\gamma-1$, each older generation consumer consumes $\frac{1}{2 \gamma}[1+(\gamma-1) \tau]$ units of the good by his savings and the pay-as-you-go pension $(\tau)$. Let $G^{t}$ be the government expenditure other than the pay-as-you-go pension. The total demand for the good is

$$
2\left(1+\frac{1}{\gamma}\right)[1+(\gamma-1) \tau]+G^{t} .
$$

Note that there are four younger and four older generation consumers. This must be equal to the total supply, 4. Thus,

$$
G^{t}=\frac{2(\gamma-1)}{\gamma}[1-(1+\gamma) \tau]>0 .
$$

The total net savings of the older generation consumers, which is the difference between their consumptions and the pensions, is

$$
\frac{2}{\gamma}[1+(\gamma-1) \tau]-4 \tau=\frac{2}{\gamma}[1-(1+\gamma) \tau] .
$$

On the other hand, the total net savings of the older generation consumers in the next period, who are the younger generation consumers in Period $t$, is

$$
2[1+(\gamma-1) \tau]-4 \gamma \tau=2[1-(1+\gamma) \tau] .
$$

The difference between (10) and (9) is

$$
\frac{2}{\gamma}(\gamma-1)[1-(1+\gamma) \tau]=G^{t}
$$

Therefore, the government expenditure $G^{t}$ in (8) equals the increase in the net savings of the consumers from Period $t-1$ to Period $t$.

Is the pair of strategies above in a Nash equilibrium?

1. Firm: given the consumption behavior of the younger generation consumers and the older generation consumers, and the government expenditure, employment of four consumers and production of four units of the good are optimal.

2. Each younger generation consumer: given the behavior of the firm, consumptions of the other consumers and the government expenditure, supply of one unit of labor and $\frac{1}{2}[1+(\gamma-1) \tau]$ units of consumption are optimal under the assumption that each consumer spends half of his income, respectively, on consumption in Period 1 and that in Period 2. 


\subsubsection{Period $t+1$}

Next we consider Period $t+1$. Suppose that the labor productivity in Period $t+1$ is $\gamma-1$, and the nominal wage rate is also $\gamma-1$. Let us consider the following pair of strategies of the firm and the younger generation consumers in Period $t+1$. The pay-as-you-go pension for each older generation consumer is $\gamma \tau$.

1. Firm: employs four younger generation consumers and produces $4 \gamma$ units of the good.

2. Each employed younger generation consumer: supplies one unit of labor, receives wage $\gamma$, consumes $\frac{\gamma}{2}[1+(\gamma-1) \tau]$ units of the good, pays $\gamma \tau$ units of tax for the pay-as-you-go pension system for the older generation consumers, who are the younger generation consumers in Period $t$, and leaves the rest of the income;

$$
\frac{\gamma}{2}[1-(1+\gamma) \tau]
$$

In the next period he consumes $\frac{\gamma}{2}[1+(\gamma-1) \tau]$ units of the good by his savings and the pay-asyou-go pension $\gamma^{2} \tau$.

Each older generation consumer consumes $\frac{1}{2}[1+(\gamma-$ 1) $\tau$ ] units of the good by his savings and the pay-asyou-go pension $(\gamma \tau)$. Let $G^{t+1}$ be the government expenditure other than the pay-as-you-go pension. The total demand for the good is

$$
2(1+\gamma)[1+(\gamma-1) \tau]+G^{t+1} .
$$

This must be equal to the total supply, $4 \gamma$. Thus,

$$
G^{t+1}=2(\gamma-1)[1-(1+\gamma) \tau]=\gamma G^{t} .
$$

The government expenditure $G^{t+1}$ in (12) equals the increase in the net savings of the consumers from Pe$\operatorname{riod} t$ to Period $t+1$. This relationship holds true even after Period $t+1$.

Is the pair of strategies above in a Nash equilibrium?

1. Firm: given the consumption behavior of the younger generation consumers and the older generation consumers, and the government expenditure, employment of four consumers and production of $4 \gamma$ units of the good are optimal.

2. Each younger generation consumer: given the behavior of the firm, consumptions of the other consumers and the government expenditure, supply of one unit of labor and $\frac{\gamma}{2}[1+(\gamma-1) \tau]$ units of consumption are optimal under the assumption that each consumer spends half of his income, respectively, on consumption in Period 1 and that in Period 2.
From these results we get the following proposition.

Proposition 6. In order to maintain economic growth we need sustained budget deficits. The budget deficit in each period equals the increase in the total net savings of the older generation consumers (the difference between their consumptions and the pensions) from the previous period to this period.

\subsection{Inflation by excessive budget deficit}

\subsubsection{Period $t$}

In this subsection we suppose that the government expenditure in Period $t$ is larger than $G^{t}$ in the previous case. Denote it by $\hat{G}^{t}$. The actual price of the good in Period $t$ is $\rho>1$, and the actual nominal wage rate is also $\rho$. We assume that the inflation is not anticipated by the older generation consumers in the previous period (when they are young in their Period 1). We consider the value of $\hat{G}^{t}$ which triggers inflation at the rate $\rho$ under full-employment. Let us consider the following pair of strategies of the firm and the younger generation consumers.

1. Firm: employs four younger generation consumers and produces four units of the good.

2. Each employed younger generation consumer: supplies one unit of labor, receives wage $\rho$, consumes $\frac{1}{2}[1+(\gamma-1) \tau]$ units of the good at the price $\rho$, pays $\rho \tau$ units of tax for the pay-as-yougo pensions for the older generation consumers, and leaves the rest of the income;

$$
\rho-\rho \tau-\frac{\rho}{2}[1+(\gamma-1) \tau]=\frac{\rho}{2}[1-(1+\gamma) \tau] .
$$

In the next period he consumes $\frac{1}{2}[1+(\gamma-1) \tau]$ units of the good by his savings and the pay-asyou-go pension $\rho \gamma \tau$ at the price $\rho$ if the price of the good is $\rho$ in Period $t+1$.

Each older generation consumer consumes $\frac{1}{2 \rho \gamma}[1+$ $(\rho \gamma-1) \tau]$ units of the good by his savings and the pay-as-you-go pension $(\rho \tau)$. The nominal total demand for the good is

$$
\begin{aligned}
& 2 \rho[1+(\gamma-1) \tau]+\frac{2}{\gamma}[1+(\rho \gamma-1) \tau]+\hat{G}^{t} \\
= & \frac{2}{\gamma}\left[1+\rho \gamma+\left(\rho \gamma^{2}-1\right) \tau\right]+\hat{G}^{t} .
\end{aligned}
$$

If this is equal to the nominal total supply, $4 \rho$, we have

$$
\hat{G}^{t}=\frac{2}{\gamma}\left[\rho \gamma-1-\left(\rho \gamma^{2}-1\right) \tau\right] .
$$


Comparing this with $G^{t}$ in (8),

$$
\begin{aligned}
& \hat{G}^{t}-G^{t} \\
& =\frac{2}{\gamma}\left\{\rho \gamma-1-\left(\rho \gamma^{2}-1\right) \tau-(\gamma-1)[1-(1+\gamma) \tau]\right\} \\
& =2(\rho-1)(1-\gamma \tau)>0 .
\end{aligned}
$$

This means that an excessive budget deficit expressed in (13) causes inflation under full-employment.

Is the pair of strategies above in a Nash equilibrium?

1. Firm: given the consumption behavior of the younger generation consumers and the older generation consumers, and the government expenditure, employment of four consumers and production of four units of the good are optimal.

2. Each younger generation consumer: given the behavior of the firm and consumptions of the other consumers, supply of one unit of labor and $\frac{1}{2}[1+(\gamma-1) \tau]$ units of consumption are optimal under the assumption that each consumer spends half of his income, respectively, on consumption in Period 1 and that in Period 2. tion.

From these results we get the following proposi-

Proposition 7. The excessive budget deficit expressed in (13) causes inflation under fullemployment.

\subsubsection{Period $t+1$}

Next we consider Period $t+1$. Suppose that the labor productivity in Period $t+1$ is $\gamma$, and the nominal wage rate is $\rho \gamma$. Let us consider the following pair of strategies of the firm and the younger generation consumers in Period $t+1$. The pay-as-you-go pension for each older generation consumer is $\rho \gamma \tau$. Assume that the price of the good in this period is $\rho$.

1. Firm: employs four younger generation consumers and produces $4 \gamma$ units of the good.

2. Each employed younger generation consumer: supplies one unit of labor, receives wage $\rho \gamma$, consumes $\frac{\gamma}{2}[1+(\gamma-1) \tau]$ units of the good at the price $\rho$, pays $\rho \gamma \tau$ units of tax for pay-as-you-go pension to the older generation consumers, who are the younger generation consumers in Period $t$, and leaves the rest of the income;

$\rho \gamma-\rho \gamma \tau-\frac{\rho \gamma}{2}[1+(\gamma-1) \tau]=\frac{\rho \gamma}{2}[1-(1+\gamma) \tau]$.

In the next period he consumes $\frac{\gamma}{2}[1+(\gamma-1) \tau]$ units of the good by his savings and the pay-asyou-go pension $\rho \gamma^{2} \tau$ at the price $\rho$.
Each older generation consumer consumes $\frac{1}{2}[1+(\gamma-$ 1) $\tau]$ units of the good by his savings and the pay-asyou-go pension $(\rho \gamma \tau)$ at the price $\rho$. Let $\hat{G}^{t+1}$ be the government expenditure other than the pay-as-you-go pension. The nominal total demand for the good is

$$
2 \rho(1+\gamma)[1+(\gamma-1) \tau]+\hat{G}^{t+1} .
$$

This must be equal to the nominal total supply, $4 \rho \gamma$. Thus,

$$
\hat{G}^{t+1}=2 \rho(\gamma-1)[1-(1+\gamma) \tau] .
$$

From (12) we find

$$
\hat{G}^{t+1}=\rho G^{t+1} .
$$

This relationship holds true even after Period $t+1$. Therefore, after one period inflation full-employment under constant price is maintained by sustained budget deficits. Only the excess portion should be reduced. There is no need to make up for past excesses by creating surpluses or reducing deficits.

Is the pair of strategies above in a Nash equilibrium?

1. Firm: given the consumption behavior of the younger generation consumers and the older generation consumers, and the government expenditure, employment of four consumers and production of $4 \gamma$ units of the good are optimal.

2. Each younger generation consumer: given the behavior of the firm, consumptions of the other consumers and the government expenditure, supply of one unit of labor and $\frac{\gamma}{2}[1+(\gamma-1) \tau]$ units of consumption are optimal under the assumption that each consumer spends half of his income, respectively, on consumption in Period 1 and that in Period 2.

From these results we obtain the following proposition.

Proposition 8. After one period inflation fullemployment under constant price is maintained by sustained budget deficits. Only the excess portion should be reduced. There is no need to make up for past excesses by creating surpluses or reducing deficits.

\subsection{Insufficient budget deficit and recovery from recession}

\subsubsection{Period $t$}

Now we assume that the government expenditure in Period $t$ is insufficient. Let the actual value of the government expenditure be

$$
\tilde{G}^{t}=\frac{2}{\gamma}(\gamma-1)[1-(1+\gamma) \tau]-\frac{1}{2} .
$$


It is smaller than $G^{t}$ in (8). We assume that it is nonnegative. The price of the good and the nominal wage rate in Period $t$ is 1 . We also assume that upto the previous period, Period $t-1$, full-employment has been realized. Let us consider the following pair of strategies of the firm and the younger generation consumers.

1. Firm: employs three younger generation consumers and produces three units of the good.

2. Each employed younger generation consumer: supplies one unit of labor, receives wage 1, consumes $\frac{1}{2}\left[1+\left(\gamma-\frac{4}{3}\right) \tau\right]$ units of the good, pays $\frac{4}{3} \tau$ units of tax for pay-as-you-go pensions for the older generation consumers, and leaves the rest of the income:

$1-\frac{4}{3} \tau-\frac{1}{2}\left[1+\left(\gamma-\frac{4}{3}\right) \tau\right]=\frac{1}{2}\left[1-\left(\gamma+\frac{4}{3}\right) \tau\right]$.

In the next period he consumes $\frac{1}{2}\left[1+\left(\gamma-\frac{4}{3}\right) \tau\right]$ units of the good by his savings and the pay-asyou-go pension $\gamma \tau$.

3. One unemployed consumer: consumes $\frac{1}{2} \gamma \tau$ units of the good by borrowing money from employed younger generation consumers using his pension as collateral. In the next period he consumes $\frac{1}{2} \gamma \tau$ units of the good by the pay-as-you-go pension $\gamma \tau$, and repays his debt due to consumption in Period 1

Each older generation consumer consumes $\frac{1}{2 \gamma}[1+$ $(\gamma-1) \tau]$ units of the good by his savings and the payas-you-go pension $(\tau)$. The total demand for the good is

$$
\begin{aligned}
& \frac{3}{2}\left[1+\left(\gamma-\frac{4}{3}\right) \tau\right]+\frac{1}{2} \gamma \tau \\
& +\frac{2}{\gamma}[1+(\gamma-1) \tau]+\tilde{G}^{t} \\
= & \frac{3}{2}\left[1+\left(\gamma-\frac{4}{3}\right) \tau\right]+\frac{1}{2} \gamma \tau+\frac{2}{\gamma}[1+(\gamma-1) \tau] \\
& +\frac{2}{\gamma}(\gamma-1)[1-(1+\gamma) \tau]-\frac{1}{2}=3 .
\end{aligned}
$$

Note that there are four older generation consumers, three employed and one unemployed younger consumers. (14) means that the total demand equals the total supply, and there exists one involuntary unemployment.

Are the strategies of the firm and the younger generation consumers above in a Nash equilibrium?
1. Firm: given the consumption behavior of the younger generation consumers and the older generation consumers, and the government expenditure, employment of three consumers and production of three units of the good are optimal.

2. Each younger employed consumer: given the behavior of the firm, consumptions of the other consumers and the government expenditure, supply of one unit of labor and $\frac{1}{2}\left[1+\left(\gamma-\frac{4}{3}\right) \tau\right]$ units of consumption are optimal under the assumption that each consumer spends half of his income, respectively, on consumption in Period 1 and that in Period 2.

3. One younger unemployed consumer: given the behavior of the firm, consumptions of the other consumers and the government expenditure, $\frac{1}{2} \gamma \tau$ units of consumption is optimal given the situation that he is unemployed, and spends half of his income, respectively, on consumption in Period 1 and that in Period 2.

From these results we get the following proposition.

Proposition 9. The insufficient government expenditure (or budget deficit) causes involuntary unemployment.

\subsubsection{Period $t+1$}

Next we consider Period $t+1$. Suppose that we recover full-employment in Period $t+1$ by increasing the government expenditure (or the budget deficit). Let $\tilde{G}^{t+1}$ be the government expenditure other than the pay-as-you-go pension which is sufficient to recover full-employment.

Suppose that the labor productivity in Period $t+1$ is $\gamma$, and the nominal wage rate is $\gamma$. Let us consider the following pair of strategies of the firm and the younger generation consumers in Period $t+1$. The pay-as-you-go pension for each older generation consumer is $\gamma \tau$. Assume that the price of the good in this period is 1 .

1. Firm: employs four younger generation consumers and produces $4 \gamma$ units of the good.

2. Each employed younger generation consumer: supplies one unit of labor, receives wage $\gamma$, consumes $\frac{\gamma}{2}[1+(\gamma-1) \tau]$ units of the good, pays $\gamma \tau$ units of tax for pay-as-you-go pension for the older generation consumers, who are the younger generation consumers in Period $t$, and leaves the rest of the income;

$$
\gamma-\gamma \tau-\frac{\gamma}{2}[1+(\gamma-1) \tau]=\frac{\gamma}{2}[1-(1+\gamma) \tau] .
$$


In the next period he consumes $\frac{\gamma}{2}[1+(\gamma-1) \tau]$ units of the good by his savings and the pay-asyou-go pension $\gamma^{2} \tau$.

Each older generation consumer, who was employed in the previous period, consumes $\frac{1}{2}\left[1+\left(\gamma-\frac{4}{3}\right) \tau\right]$ units of the good by his savings and the pay-as-yougo pension $(\gamma \tau)$, and one older generation consumer, who was unemployed in the previous period, consumes $\frac{1}{2} \gamma \tau$ units of the good by the pay-as-you-go pension. He also repay the debt for consumption in the previous period.

The total demand for the good is

$2 \gamma[1+(\gamma-1) \tau]+\frac{3}{2}\left[1+\left(\gamma-\frac{4}{3}\right) \tau\right]+\frac{1}{2} \gamma \tau+\tilde{G}^{t+1}$.

Note that there are three older generation consumers who was employed, and one of them was unemployed. Suppose that this is equal to the total supply, $4 \gamma$. Then,

$$
\tilde{G}^{t+1}=2(\gamma-1)[1-(1+\gamma) \tau]+\frac{1}{2} .
$$

Comparing this with (12)

$$
\tilde{G}^{t+1}-G^{t+1}=\frac{1}{2}>0 .
$$

Therefore, to recover full-employment from a state with involuntary unemployment we need extra budget deficit. After recovery of full-employment we can maintain it with sustained budget deficit. Thus, the extra budget deficit should not be redeemed.

Is the pair of strategies above in a Nash equilibrium?

1. Firm: given the consumption behavior of the younger generation consumers and the older generation consumers, and the government expenditure, employment of four consumers and production of $4 \gamma$ units of the good are optimal.

2. Each younger generation consumer: given the behavior of the firm, consumptions of the other consumers and the government expenditure, supply of one unit of labor and $\frac{\gamma}{2}[1+(\gamma-1) \tau]$ units of consumption are optimal under the assumption that each consumer spends half of his income, respectively, on consumption in Period 1 and that in Period 2. sition.

From these results we obtain the following propo-

Proposition 10. In order to recover full-employment from a state with involuntary unemployment we need extra budget deficit. After recovery of fullemployment we can maintain it with sustained budget deficit. Thus, the extra budget deficit should not be redeemed.

\section{Conclusion}

This paper attempts to provide a game-theoretic basis to functional finance theory and MMT (Modern Monetary Theory). We have shown that to achieve and maintain full-employment in a growing economy we need sustained budget deficits even without inflation, and this budget deficit must not be redeemed. The model of this paper is very simple. For example there is no capital and investment. In the future research we would like to consider a model in which firms make investments.

References:

[1] T. Hogan. Review of Stephanie Kelton $\square$ fs the Deficit Myth. AIER Sound Money Project Working Paper No. 2021-5, 2021.

[2] S. Kelton. The Deficit Myth: Modern Monetary Theory and the Birth of the People's Economy. Public Affairs, 2020.

[3] A. P. Lerner. Functional finance and the federal debt. Social Research, 10:38-51, 1943.

[4] A. P. Lerner. The Economics of Control: Principles of Welfare Economics. Macmillan, 1944.

[5] W. Mitchell, L. R. Wray, and M. Watts. Macroeconomics. Red Gbole Press, 2019.

[6] M. Otaki. The dynamically extended Keynesian cross and the welfare-improving fiscal policy. Economics Letters, 96:23-29, 2007.(https:// doi.org/10.1016/j.econlet.2006.12.005)

[7] M. Otaki. A welfare economics foundation for the full-employment policy. Economics Letters, 102:1-3, 2009.(https://doi.org/10. 1016/j.econlet. 2008.08.003)

[8] M. Otaki. Keynsian Economics and Price Theory: Re-orientation of a Theory of Monetary Economy. Springer, 2015.

[9] Y. Tanaka. Involuntary unemployment with indivisible labor supply under perfect competition. Economics Bulletin, 40:1914-1923, 2020.(http: //www.accessecon. com/Pubs/EB/2020/ Volume40/EB-20-V40-I3-P165.pdf)

[10] Y. Tanaka. An Elementary Mathematical Model for MMT (Modern Monetary Theory). Research in Applied Economics. 13:1-20. 2021. (https: //doi.org/10.5296/rae.v13i3.18989)

[11] Y. Tanaka. Necessity of Budget Deficit Under Economic Growth in Monopolistic Competition. Economics and Business, 36:116. 2022. (https://doi.org/10.5296/rbm. v9i1.19541) 
[12] Y. Tanaka. On Budget Deficit under Economic Growth: Towards a Mathematical Model of MMT. International Journal of Social Science Research. 10:36-58, 2022. (https://doi .org/ 10.5296/ijssr.v10i1.19130)

\section{Sources of funding for research presented in a scientific article or scientific article itself}

This work was supported by JSPS KAKENHI Grant Number 18K01594 in Japan.

Creative Commons Attribution License 4.0 (Attribution 4.0 International, CC BY 4.0)

This article is published under the terms of the Creative Commons Attribution License 4.0

https://creativecommons.org/licenses/by/4.0/deed.en US 